\title{
$\alpha$-Chymotrypsin catalysed oligopeptide synthesis for hair modelling
}

\author{
Madalena Martins, Carla Silva, Artur Cavaco-Paulo* \\ Centre of Biological Engineering (CEB), University of Minho, Campus of Gualtar, 4710-057, Braga, Portugal
}

\section{A R T I C L E I N F O}

\section{Article history:}

Received 15 April 2019

Received in revised form

9 July 2019

Accepted 21 July 2019

Available online 22 July 2019

Handling editor: M.T. Moreira

\section{Keywords:}

Catalysis

Oligopeptide

Coating

Hair modelling

\begin{abstract}
A B S T R A C T
Conventional chemical treatments imply the use of harsh chemicals which can cause serious adverse effects on consumers' health, hair fibre and environment. In this work was reported for the first time the modelling shape of Asian hair by oligopeptide coating synthesized by a protease. $\alpha$-Chymotrypsin from Bovine pancreas catalysed the oligomerization of the tri-peptides, KCL (Lysine-Cysteine-Leucine) ethyl ester and KSL (Lysine-Serine-Leucine) ethyl ester in aqueous media. The synthesis reaction gave rise to oligopeptides with $\mathrm{DP}=6$, which were characterized by mass spectra (MALDI-TOF). The in situ synthesis reaction onto the hair surface, under controlled $\mathrm{pH}(8.5-9)$ and temperatures between $25^{\circ} \mathrm{C}$ and $55^{\circ} \mathrm{C}$, formed a coating layer inducing changes in the hair shape from straight to curly. Qualitative and quantitative characterization of coated hair was performed by image visualization and by perming efficiency assessment. The developed strategy revealed to be a safer and cleaner alternative to the conventional chemical treatments generally used for hair shape modification. Low cost associated to the catalyst and lower side effects to the hair fibre, health consumer and environment might lead to the development of a cost-effective and sustainable approach in the hair care industry.
\end{abstract}

๑) 2019 Elsevier Ltd. All rights reserved.

\section{Introduction}

Keratin proteins derived from several sources including hair, wool and epithelial tissues, are distinguished by the presence of a large amount of cysteine residues. Human hair is composed by around $80 \%$ of keratin with a high amount of sulphur atoms derived from cysteine amino acid (de Cássia Comis Wagner and Joekes, 2005). Formation of cystines renders high formation of disulphide bonds between hair keratins promoting valuable mechanical, chemical and thermal properties (Cruz, C. et al., 2016; Yu et al., 1993). The formation of disulphide bonds is imperative when morphological modification of human hair is required. Hence, controlling the disruption of disulphide crosslinks is crucial to change the shape of high crosslinked proteins as the human hair keratin. The inherent stability of macromolecular keratin structure derives from a range of strong to weak interactions, such as disulphide bonds to hydrogen bonds and hydrophobic interactions. Those covalent bonds remain intact in the presence of water, otherwise, weaker interactions are easily broken by water (Wolfram, 2003). Changing properties of natural macromolecules,

\footnotetext{
* Corresponding author. Universidade do Minho, Campus de Gualtar, 4710-057, Braga, Portugal.

E-mail address: artur@deb.uminho.pt (A. Cavaco-Paulo).
}

as modifying their appearance and their performance properties has attracting growing interest, from academic to industrial scientists (Elias, 2013). When modification of natural macromolecules is required, health care and durability settings are key points in multiple methodologies. For example, in antimicrobial or antiwrinkle properties of cotton, wool and silk in textile applications (Nogueira et al., 2014; Nourbakhsh and Ashjaran, 2012; Qi et al., 2016; Shirgholami et al., 2016), and in alternative treatment for hair in cosmetic styling processes (Cruz et al., 2017a; Fernandes and Cavaco-Paulo, 2012).

The desire for beautiful and healthy hair has been the driving force of hair care industry. Huge hair care products have been developed to improve its structural integrity. However, successful cosmetic treatments to alter hair shape require chemical processes (Harrison and Sinclair, 2003; Sinclair, 2007). Usually, the chemical treatments to change the shape of the hair, straightening or perming treatments, are based on reductive agents (e.g thioglycolic acid, sodium hydroxide, guanidine hydroxide, among others) in the reduction phase, and based on oxidizing agents (e.g hydrogem peroxide) in the neutralization phase. Other chemical styling methods as colouring or bleaching can also result in hair fibre damages altering its properties (Lee et al., 2014). These chemical processes make permanent changes on the hair structure and lead to severe hair fibre damaging (Galli et al., 2015; Kaur et al., 2002; Maneli et al., 2014b; McMichael, 2007; Miranda-Vilela et al., 
2014). As a result of the damage, hair changes its physicalmechanical properties leading to reduced cross-linking density (Dyer et al., 2013; Robbins, 2002). Extremely damaged hair may suffer from the appearance of crack and lifting of the cuticle, removal of the hair cuticle hydrophobic top-layer, and consequent reduction of surface hydrophobicity (Cruz et al., 2017b). Diffusion rate into keratin fibres, which is dependent on the crosslink density of the hair, is altered in damaged hair. Hence, excessive or repeated hair chemical treatments with these harsh chemicals may damage the hair fibre (Cruz, C.F. et al., 2016; McMichael, 2007; Olasode, 2009), the health of the consumer and stylist and even the release of toxic elements into the environment (Cruz et al., 2017a; Galli et al., 2015; Kaur et al., 2002; Maneli et al., 2014a). The use of peptides for hair keratin treatment has been explored (Fernandes and Cavaco-Paulo, 2012; Gavazzoni Dias, 2015; Villa et al., 2013). Their high ability to diffuse into the hair keratin layers and high cysteine content are intended to improve hair properties.

Peptides have been investigated as alternative to chemicals in hair cosmetic applications (Cruz et al., 2017b) and components of soft materials prepared by self-assembly (Li et al., 2008), among other fields of importance. Current drawback of protease-catalysis of amino acid esters has been the high expression on oligopeptide synthesis. Protease has been used as catalyst for peptide synthesis reaction displaying inherent positive properties as mild reaction conditions, the activation involves simple formation of ethyl esters, high regio-specificity and stereo-specificity avoiding steps of protection and deprotection (Bongers and Heimer, 1994; Gill et al., 1996; Hans-Dieter et al., 1985; Li et al., 2008). The associated cost of these reactions is considerable lower when compared to the chemical or fermentation methods. Peptide synthesis by protease-catalysis has been successfully achieved using dipeptides (Bordusa, 2002; Qin et al., 2011, 2013a, 2013b). Herein the focus was the oligomerization of two tri-peptides by catalysis with a protease, $\alpha$-chymotrypsin, proposing a greener route for the coating of hair envisaging its shape modelling. Since no hazards reagents are used, the proposed approach show great potentiality for hair industry processing.

\section{Material and methods}

\subsection{Materials}

Tri-peptide KCL-Oet (Lys-Cys-Leu-OEt) and tri-peptide KSL-OEt (Lys-Ser-Leu-OEt) were kindly synthesized by Biobasic. Sodium phosphate dibasic, sodium phosphate monobasic, $\alpha$-chymotrypsin from Bovine pancreas (Type II, lyophilized powder, $\geq 40$ units $/ \mathrm{mg}$ protein) and $\alpha$-cyanohydroxycinnamic acid (CHCA, MALDI-TOF matrix) were purchased from Sigma-Aldrich and was used as received. Hair samples were collected from two volunteers (female) originated from Asia. The Asian hair samples were taken from each volunteer, collected around $200 \mathrm{mg}$ per each sample condition. All reagents were used as received.

\subsection{Characterization of oligopeptides (KCL and KSL) synthesised in} aqueous media by MALDI-TOF (matrix assisted laser desorption ionization time-of-flight)

The protease selected as catalyst for the tri-peptide ethyl esters (KCL-OEt and KSL-OEt) oligomerization was the protease, $\alpha$ chymotrypsin from bovine pancreas. The oligomerization was conducted by placing $0.3 \mathrm{M}$ both tripeptides individually in $0.2 \mathrm{M}$ phosphate buffer, $\mathrm{pH} 8.5-9$, at $40^{\circ} \mathrm{C}$, for 1 min. Afterwards, the $\alpha$ chymotrypsin was added $(10 \mathrm{mg} / \mathrm{mL})$ to this solution and the reaction proceed by a vortex mixer agitation. The reaction mixture was analysed by mass spectra. MALDI-TOF spectra was obtained on a Bruker Autoflex Speed instrument (Bruker Daltonics, GmbH) equipped with a $337 \mathrm{~nm}$ nitrogen laser. To generate the matrix solutions, a saturated solution of $\alpha$-cyano-4-hydroxycinnamic acid (CHCA) and of sinapic acid were prepared in solvent TA30 (30:70[v/ v] acetonitrile:trifluoroacetic acid ( $1 \%$ in water). Oligopeptide samples were dissolved $100 \mu \mathrm{L}$ of saturated matrix solution. Then, samples were mixed with the matrixes (1:1) and applied onto a ground steel target plate (Bruker part $n^{\circ}$ 209519). Samples were analysed in the linear mode using factory-configured instrument parameters suitable for a $1-10 \mathrm{kDa} / \mathrm{z}$ range (ion source 1 : $19,5 \mathrm{kV}$; ion source $2: 18,3 \mathrm{kV}$ ). Time delay between laser pulse and ion extraction was set to $130 \mathrm{~ns}$, and the laser frequency was $5 \mathrm{~Hz}$. The number average molecular weight $(\mathrm{Mn})$ and weight average molecular weight (Mw) was obtained directly from MALDI-TOF analysis according to the well-known equations (Li, 2009).

\subsection{In situ coating of Asian hair with oligopeptides}

Before coatings, the hair samples were shampooed, rinsed and dried at room temperature. Coating of tri-peptides involved two main events, namely swelling and oligomerization/coating. The tripeptide ethyl esters catalyzed by $\alpha$-chymotrypsin were applied onto Asian hair fibre and the oligomerization process occurred directly onto the hair fibre following two methodologies. Firstly, the straight Asian hair was rolled onto a glass rod followed by a pretreatment at alkaline $\mathrm{pH}$ (adjusted with phosphate buffer), and dried with a blow-dry (with temperature control $25-55^{\circ} \mathrm{C}$ ); then the tri-peptide was applied at $\mathrm{pH} 8.8$ and the catalyst was added; afterwards, the hair samples were blow-dried at temperatures from 25 to $55^{\circ} \mathrm{C}$ for the coating development; the drying step was finalized with higher temperatures $\left(55-85^{\circ} \mathrm{C}\right)$. The hair was then removed from the glass rod and the length and the number of loops after and before coating treatment was measured. The second methodology applied was similar to the described previously differing in the generation of the curls. A babyliss equipment with fixed temperature at $200^{\circ} \mathrm{C}$ was used. After coating perming efficiency for each hair sample was calculated (Equation (1)).

The hair samples were also subjected to the conventional chemical treatment as a control process consisting in a strong alkali which breaks the disulphide bonds. From the broken disulphide bonds, the state of hair fibre's changes to a new hair shape style which in turns in a permanent style after neutralization to rearrange the disulphide bonds. Thus, the chemical treatment, consisted in two main steps: reduction and neutralizing. In the first step, the straight hair was wrapped around rods to generate curls, and a basic solution of ammonium thioglycolate was applied for $20 \mathrm{~min}$. The reduced hair was rinsed with water and dried with a towel. The second step involved the oxidation reaction using a neutralizer agent (based on hydrogen peroxide). Finally, the hair was rinsed thoroughly with water and dried with blow drier.

Perming efficiency (PE) was calculated using equation (4).

$P E=\frac{n^{\circ} \text { loops after treatment } / \text { fiber lenght after treatment }}{n^{\circ} \text { loops before treatment } / \text { fiberlenght before treatment }} \times 100$

\subsection{Morphological evaluation of coated hair by scanning electron microscopy (SEM)}

Hair samples were placed onto a specimen slide followed by coating with a thin layer of gold. Slides were examined by SEM (Phenom-World BV, Netherlands) at 3000x magnification. The hair surface damage was evaluated by a SEM standard grading system described by Kim et al. (2010). 


\subsection{Free thiol and disulphide bonds determination}

The total content of free thiol groups in the hair samples was carried out according to the spectrophotometric method using 5,5' dithiobis(2-nitrobenzoic acid) (Ellman's reagent) described by Ellman (1959). Briefly, hair samples (10 mg) were suspended in $5 \mathrm{~mL}$ of phosphate buffer (0.5 M, pH 8.0) containing $100 \mu \mathrm{L}$ of $4 \mathrm{mg} / \mathrm{mL}$ Ellman's reagent solution. Samples were incubated in dark at room temperature for $1 \mathrm{~h}$. Then, its absorbance was read at a wavelength of $412 \mathrm{~nm}$ using a UV/vis spectrometer. Determination of free thiol groups were obtained from a calibration curve using L-cysteine standards. Similar reaction method using Ellman's reagent was performed to determine the total amount of sulphur in the hair samples. To that, a complete reduction of disulphide bonds was performed using sodium borohydride (Hansen et al., 2007). Briefly, about $10 \mathrm{mg}$ of hair sample was hydrated in water $(350 \mu \mathrm{L}$, for $10 \mathrm{~min}$ ) following $150 \mu \mathrm{L}$ of Tris buffer $(0.05 \mathrm{M}, \mathrm{pH} 6.8)$ and $4 \%(\mathrm{w} / \mathrm{v})$ of sodium borohydride in $\mathrm{NaOH}(0.2 \mathrm{M})$. Samples were incubated at $37^{\circ} \mathrm{C}$ in a shaking water bath for $1 \mathrm{~h}$. The inactivation of residual sodium borohydride was performed adding $\mathrm{HCl}$ ( $5 \mathrm{M}$, for $10 \mathrm{~min}$ ) to the reaction mixture. The $\mathrm{pH}$ of the final reaction solution was adjusted to 8.0 with phosphate buffer $(1 \mathrm{M})$ and was added Ellman's reagent $(4 \mathrm{mg} / \mathrm{mL})$. Samples were incubated at room temperature for $15 \mathrm{~min}$. The amount of thiol groups were obtained as described above measuring the absorbance at $412 \mathrm{~nm}$ of wavelength. Three replica experiments were conducted for each data point.

The number of disulphide bonds presented in hair samples was determined by subtraction between free thiol group content before and after sodium borohydride reduction.

\section{Results and discussion}

\subsection{Oligopeptides characterization}

Proteases as papain, bromelain and $\alpha$-chymotrypsin, have been used as catalysts for the co-oligomerization of hydrophobic amino acid ethyl esters, namely L-leucine ethyl ester with L-glutamic acid diethyl ester hydrochloride or L-phenylalanine ethyl ester (Li et al., 2008; Qin et al., 2013a; Uyama et al., 2002; Viswanathan et al., 2010). In the last years, there is significant progress in proteasecatalyzed methods to synthesize oligopeptides (Illanes et al., 2010; Kobayashi and Makino, 2009; Li et al., 2008; Qin et al., 2013b). The enzymatic-triggered self-assembly based on the oligomerization of Lys-Leu ethyl esters (KL-ethyl ester) catalysed by $\alpha$ chymotrypsin was introduced by Gross and co-workers (Qin et al., 2013a, 2013b). Gross et al. described the catalysed synthesis of dipeptide in aqueous reaction medium by protease (Li et al., 2008; Qin et al., 2011, 2013a; Viswanathan et al., 2010). They obtained mixed chain oligomers self-assembled into $\beta$-sheets. Herein $\alpha$ chymotrypsin was used for the assisted oligomerization of a tripeptide ethyl ester Lys-Cys-Leu (KCL) ethyl ester. As postulated previously by Gross, the peptide synthesis reaction is $\mathrm{pH}$ dependent, being the formation of the oligopeptide favoured at alkaline conditions in the presence of protease (Bao-juan et al., 2010; Capellas et al., 1996; Meng et al., 2007). $\alpha$-Chymotrypsin was selected as catalyst due to its high specificity for the hydrolysis of peptide bonds between L (Leu) and K (Lys) (Polaina and MacCabe, 2007). The high specificity of the catalyst for aminolysis chain propagation was the crucial factor in the oligomerization where the leaving group was the ethanol. The competition between aminolysis and hydrolysis reaction at the terminal oligopeptide-OEt moieties will affect the chain length distribution.

After oligomerization, the oligopeptides were characterized by MALDI-TOF to evaluate the level of conversion (Table 1). The data
Table 1

Characterization of oligopeptides: number average molecular weight $\left(\overline{M_{n}}\right)$ and weight average molecular weight $\left(\overline{M_{w}}\right)$, polydispersity (PDI) and average degree of polymerization ( $\mathrm{DP}_{\mathrm{avg}}$ ) and maximum degree of polymerization (DPmax) (calculated by MALDI-TOF).

\begin{tabular}{llllll}
\hline & $\overline{\boldsymbol{M}_{\boldsymbol{n}}}$ & $\overline{\boldsymbol{M}_{\boldsymbol{w}}}$ & $\overline{\boldsymbol{M}_{\boldsymbol{w}}} / \overline{\boldsymbol{M}_{\boldsymbol{n}}}$ & $\mathrm{DP}_{\mathrm{avg}}$ & $\mathrm{DP}_{\max }$ \\
\hline KCL - oligopeptide & 518 & 1021 & 1.97 & 2.6 & 5.6 \\
KSL - oligopeptide & 789 & 1149 & 1.45 & 3 & 6.7 \\
\hline
\end{tabular}

achieved reveal molecular peaks for both oligopeptides corresponding to average polymerization degree of 2.6 and 3 for KCLand KSL-oligopeptide, respectively. Both peptides reached similar $\mathrm{DP}_{\text {avg }}$ of around 3, with a polydispersity index between 1,5 and 2 . The MALDI-TOF spectra of both oligopeptides, KCL and KSL, are presented in Fig. 1 which shows a distribution of the peaks up to 2228 and $2568 \mathrm{~m} / \mathrm{z}$, corresponding to 6 and 7 tripeptide units, respectively.

\subsection{In-situ coating characterization}

The stability of hair fibre derives from a variety of intra- and intermolecular crosslinks holding them together. Hydrogen, ionic and hydrophobic bonding type interactions are the most frequent bonds in the hair fibre (Ribeiro et al., 2013; Robbins, 2002; Wolfram, 2003). Disulphide crosslinks are the basis of the human hair fibre stability. Their disruption and formation is associated to changes on the physicochemical properties of the hair (Robbins, 2002). Here the ability of oligopeptide coating as modulator of hair fibre replacing the usual of chemical agents was explored. To that, tri-peptides KCL-OEt and KSL-OEt, in independent experiments, were polymerized in situ by $\alpha$-chymotrypsin onto Asian hair fibre. This reaction occurred under two different methods: in the first one, the hair was exposed at a temperature ranging from $25^{\circ} \mathrm{C}$ to $55^{\circ} \mathrm{C}$ and in the second method, the Asian hair was exposed at $200^{\circ} \mathrm{C}$. From qualitative and quantitative assessment, the oligopeptide KSL exhibited a very low ability to modify the shape of Asian hairy showing a perming efficiency of around $8 \%$, and for this reason was discarded for further experiments. The re-arrangement of disulphide bonds between cysteine residues of hair keratin protein determines changes in the structure of the hair (Cruz et al., 2017b). The absence of cysteine amino acid in KSL oligopeptide would be determinant for a negligible effect on hair shape modification, and for this reason this oligopeptide was excluded from further experiments. On the other hand, the similar DP $\max$ obtained for KCL oligopeptide, revealed high ability for hair shape modelling. The evaluation of visual and quantitative perming efficiencies of hair fibre confirm this assumption (Figs. 2 and 3, respectively).

The results obtained after treatment (Fig. 3) revealed that hair samples coated with KCL oligopeptide presented similar perming efficiencies as when treated with the commercial product, as dried with glass rod or with babyliss. After washing, the coated hair fibre wrapped in glass rod maintained its efficiency for around 60\%, hair wrapped in babyliss maintained for around $28 \%$ while with commercial product kept $100 \%$. This behaviour is associated to the temperature in which hair was exposed. When using the glass rod the hair was dried with a blow-drier at temperatures ranging from $25^{\circ} \mathrm{C}$ to $55^{\circ} \mathrm{C}$ followed by an increase of temperature up to $85^{\circ} \mathrm{C}$. While with babyliss, the hair samples were subjected to a constant temperature of $200^{\circ} \mathrm{C}$, which did not favoured the in situ enzymatic oligomerization of the KCL-OEt. Despite the decrease of the perming efficiency after washing, these results reveal a promising approach for hair modelling. The methodology developed presents several advantages compared with the commercial ones, no chemical agents are applied and it requires only one coupling step, 


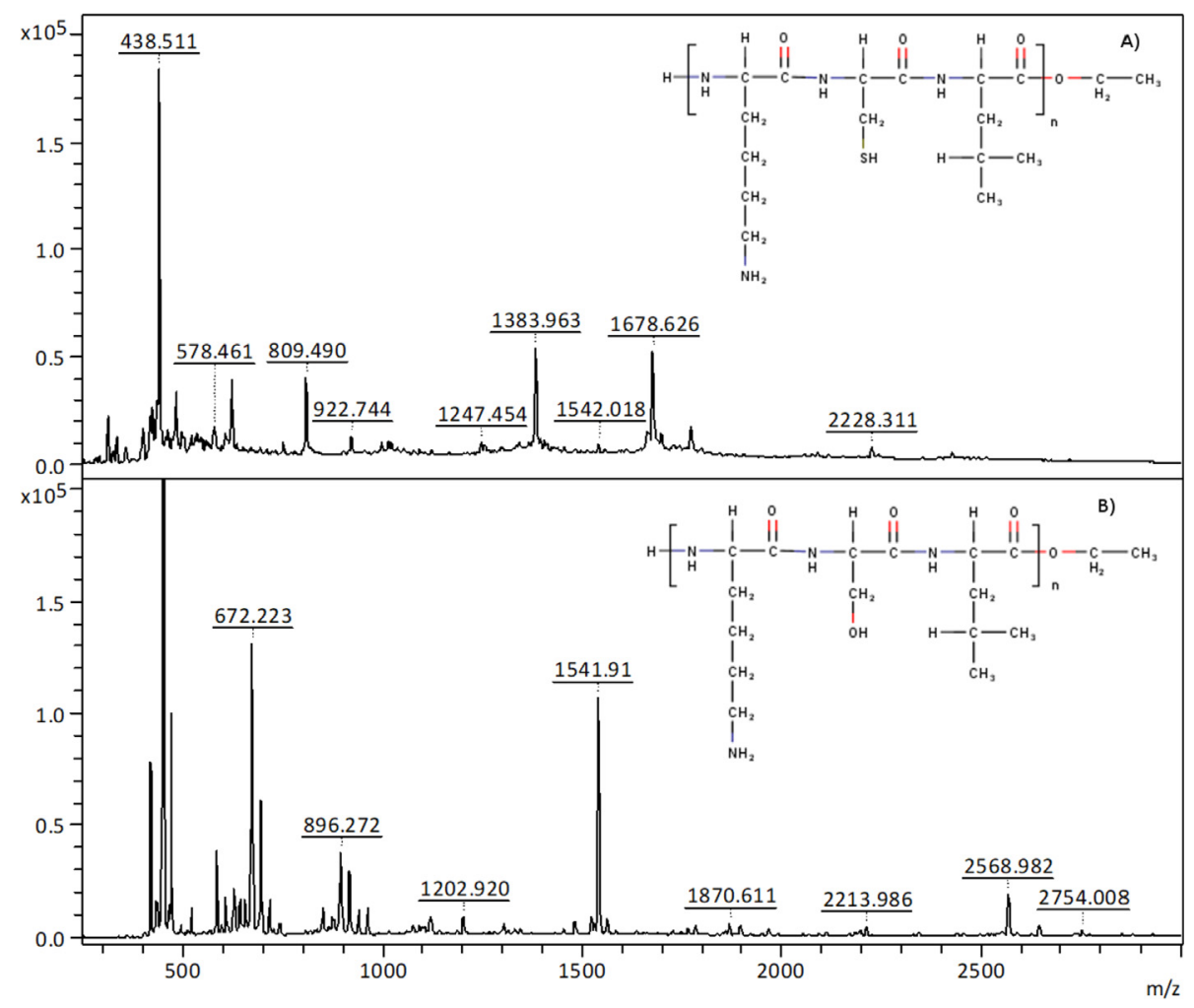

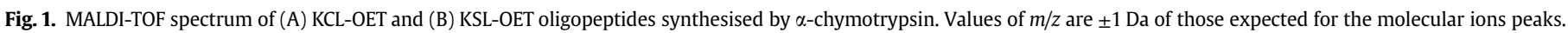
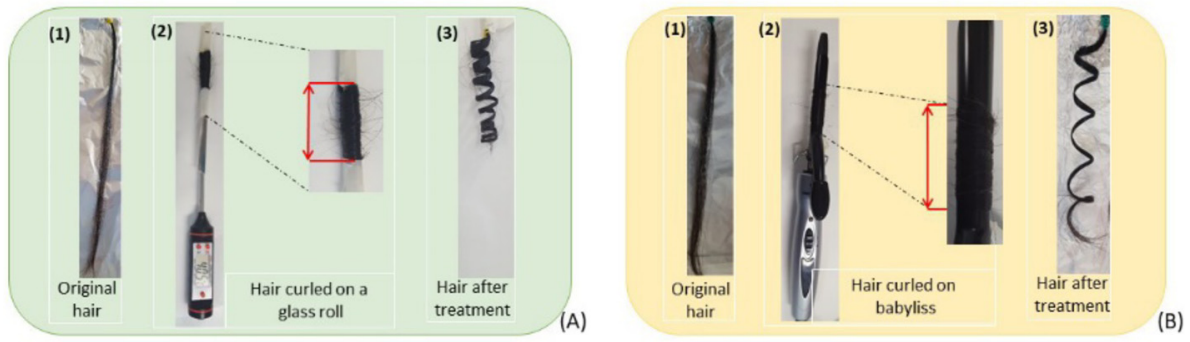

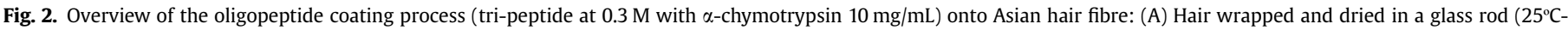
$\left.55^{\circ} \mathrm{C}, \mathrm{pH} 8.5-9\right)$ and (B) Hair wrapped and dried with babyliss $\left(200^{\circ} \mathrm{C}, \mathrm{pH} 8.5-9\right)$.

contrarily to commercial perming methods which require two steps, an high alkaline solution and a neutralization step. The use of chemicals, as alkaline reducing agents, based on thioglycolate solution, are applied to cleave and rearrange disulphide bonds rendering hair fibres more vulnerable to friction and conducting to the loss of resistance and strength (Fernandes et al., 2012; Secchi, 2008). All of these harmful effects can be avoided by using a green and controlled coating treatment based on oligomerization synthesis.

It is well-known that chemical perming agents can induce severe damage in hair fibre driving from their repeated or prolonged use. For this reason, it was imperative to evaluate the eventual damage resultant from the perming treatments developed. Table 2 presents the morphologic characterization of hair samples by scanning electron microscopy image (SEM). As expected, hair samples subjected to chemical perming treatment exhibit high patterns of damage. Lift and loss of cuticle edge was observed only in hair samples chemically permed, otherwise intact and tightly overlapping cuticle scales were observed on hair samples curled with the oligopeptide. Hair samples' surface were evaluated according a SEM standard grading system described by Kim et al. (2010). The grading scores were similar for original (virgin) and oligopeptide permed hair, both displaying a regular and intact overlay of the cuticle. For chemical permed hair was attributed the higher score corresponding to an irregular overlay of the cuticle.

The inherent benefits of oligopeptide approach to curl Asian hair are the lower treatment time and the deeply reduction of the side effects associated to health and environmental issues. The curliness efficiency after washing obtained with KCL oligopeptide coating was lower than with the chemical perming, however inducing enough morphological changes to curl the hair samples. As previously mentioned, the oligopeptide coating process is highly affected by the handling temperature. The babyliss method uses temperatures close to $200^{\circ} \mathrm{C}$ which did not favoured the coating of the oligopeptide, and after a washing step the hair samples loose almost all the curliness. Thus, the temperature was an essential parameter to control in order to induce the coating interactions between the oligopeptide and the hair keratin surface. These 


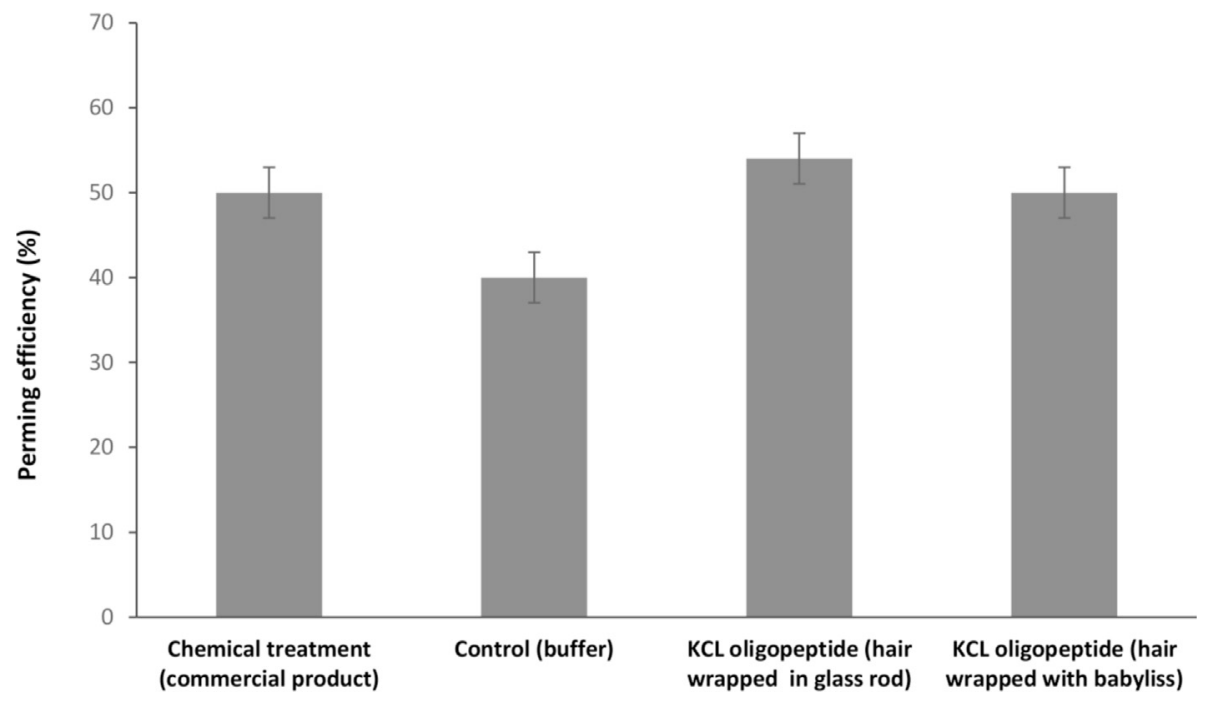

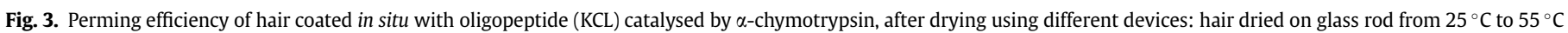
and hair dried with babyliss $200^{\circ} \mathrm{C}$; the controls presented correspond to the treatment in the presence of buffer and with the commercial chemical compound.

Table 2

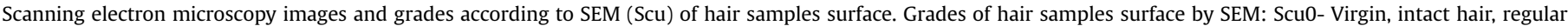

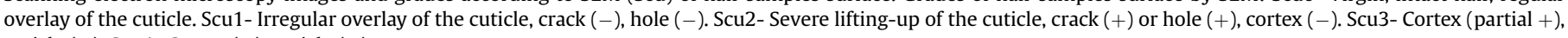
cuticle $(+)$. Scu4- Cortex $(+)$, cuticle $(-)$.

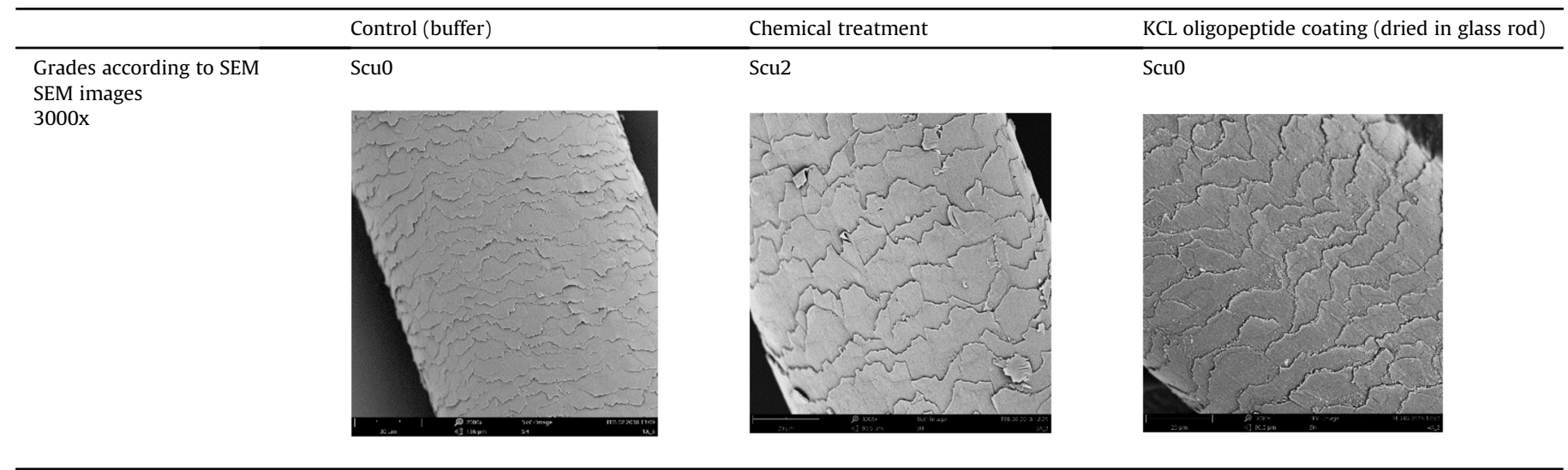

interactions were evaluated by means of disulphide bonds determination on treated hair samples. In Fig. 4 the concentration of disulphide bonds of Asian hair coated with the oligopeptide is very close to the original (raw) hair indicating that the rearrangement of the disulphide bonds after coating occurred. As expected, the chemical treatment procedure breaks the naturally occurred disulphide bonds of the hair and thereafter restores the bonds efficiently, displaying high concentration of disulphide bonds. The rearranged amount of disulphide bonds is directly related with the formation of a new configuration of the hair fibre (Lau, 1997). KCL oligopeptide-coated hair fibre changed the shape of hair fibre, however the re-formation of disulphide bonds was not as efficient as for chemical treatment. Despite this, the reformed bonds were able to confer some curliness to the hair fibre preserving its integrity. Typically, the chemical treatment is based on ammonium thioglycolate solution (perm salt) allowing the release of ammonia, which breaks the disulphide bonds by the addition of an hydrogen atom to each sulfur atom (reduction reaction). The excess of ammonia will induce the swelling of the hair keratin and thereafter the broken disulphide bonds are reformed by the action of a neutralizing agent, oxidation reaction, conferring to the hair a new shape (Bhushan, 2010; de Guzman et al., 2015).

The in situ oligopeptide coating of hair here described endow a new shape to Asian hair by creating a thin film deposition onto the hair fibre surface, fixing a new hair morphology. The pre-treatment with phosphate buffer at $\mathrm{pH} 9$ prior to coating, allowed the swelling of the fibre for a better diffusion and coating efficiency. The selected tri-peptide, KCL-OEt, contains lysine-cysteine-leucine amino acids, which after oligomerization, propagates obtaining a DP of around six $[K C L]_{6}$ (described in more detail in MALDI-TOF results section). Peptides containing cysteine residues are able to interact covalently with hair keratin proteins involving partial reconnection or disruption of disulphide linkages on hair keratin (Goddard, 1999). Cysteine is a standard amino acid with a thiol group which has a strong reducibility of disulphide bonds (Goddard, 1999; Ma et al., 2016) which can be formed spontaneously by an acceptor available, like molecular oxygen, oxidising sulfhydryl groups of the cysteine residues into disulphide bonds. The alkaline $\mathrm{pH}$ of the 


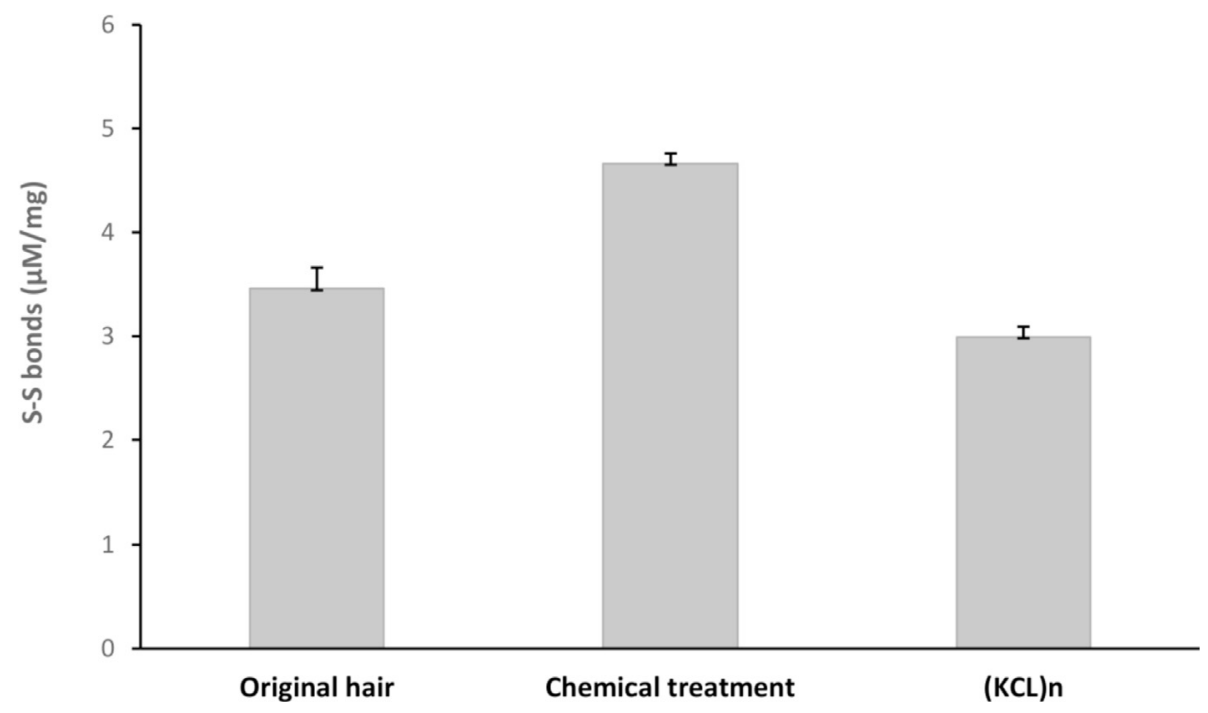

Fig. 4. Concentration of disulphide bonds in Asian hair after treatment with commercial chemical product and with KCL oligopeptide coating (dried in glass rod).

peptide reaction favoured the $[\mathrm{KCL}]_{6}$ oligomerization process and the eventual rearrangement of the disulphide bonds on hair keratin. A similar amount of disulphide bonds obtained for both, coated hair and virgin hair, confirmed the disulphide bonds rearrangement and the establishment of a new hair fibre shape.

\section{Conclusions}

The oligomerization of tri-peptide Lys-Cys-Leu (KCL) ethyl ester was successfully achieved by $\alpha$-chymotrypsin catalysis in alkaline conditions and controlled temperature. Oligopeptides with $\mathrm{DP}_{\max }=6$ and $\mathrm{DP}_{\mathrm{avg}}=3$ were obtained as confirmed by MALDI-TOF evaluation. The in situ oligopeptide coating onto keratin hair fibre induced morphological changes on its structure evidenced by visual curliness and perming efficiency. Despite the decrease of the perming efficiency after washing comparing with the chemical product, KCL oligopeptide coating demonstrates high potential in the area of hair care since no hazard chemicals are applied, the time-consuming is lower, the temperature is moderate and no is induced on hair fibre. Modelling hair shape still remains an opening and exciting challenge, and the new approach here presented offers a new perspective on induce changes in the shape of keratin hair fibre.

\section{Declarations of interest}

None.

\section{Acknowledgments}

This study was supported by the Portuguese Foundation for Science and Technology (FCT) under the scope of the strategic funding of UID/BIO/04469/2019 unit and BioTecNorte operation (NORTE-01-0145-FEDER-000004) funded by the European Regional Development Fund under the scope of Norte2020 - Programa Operacional Regional do Norte. Carla Silva acknowledges Portuguese Foundation for Science and Technology (FCT) for the funding (SFRH/IF/00186/2015).

\section{References}

Bao-juan, X., Shu-feng, S., Guo-wen, X., 2010. Protease immobilization on $\gamma$-Fe2O3/
Fe304 magnetic nanoparticles for the synthesis of oligopeptides in organic solvents. Chem. Asian J. 5 (6), 1389-1394.

Bhushan, B., 2010. Introduction-human hair, skin, and hair care products. In: Biophysics of Human Hair: Structural, Nanomechanical, and Nanotribological Studies. Springer Berlin Heidelberg, Berlin, Heidelberg, pp. 1-19.

Bongers, J., Heimer, E.P., 1994. Recent applications of enzymatic peptide synthesis. Peptides 15 (1), 183-193.

Bordusa, F., 2002. Proteases in organic synthesis. Chem. Rev. 102 (12), 4817-4868. Capellas, M., Benaiges, M.D., Caminal, G., González, G., López-Santín, J., Clapés, P. 1996. Influence of water activity and support material on the enzymatic synthesis of a cck-8 tripeptide fragment. Biocatal. Biotransform. 13 (3), 165-178.

Cruz, C., Costa, C., Gomes, A., Matamá, T., Cavaco-Paulo, A., 2016a. Human hair and the impact of cosmetic procedures: a review on cleansing and shapemodulating cosmetics. Cosmetics 3 (3), 26.

Cruz, C.F., Costa, C., Gomes, A.C., Matamá, T., Cavaco-Paulo, A., 2016b. Human hair and the impact of cosmetic procedures: a review on cleansing and shapemodulating cosmetics. Cosmetics 3 (3), 26-47.

Cruz, C.F., Martins, M., Egipto, J., Osório, H., Ribeiro, A., Cavaco-Paulo, A., 2017a. Changing the shape of hair with keratin peptides. RSC Adv. 7 (81), 51581-51592.

Cruz, C.F., Martins, M., Egipto, J., Osório, H., Ribeiro, A., Cavaco-Paulo, A., 2017b. Changing the shape of hair with keratin peptides. RSC Adv. 7 (81).

de Cássia Comis Wagner, R., Joekes, I., 2005. Hair protein removal by sodium dodecyl sulfate. Colloids Surfaces B Biointerfaces 41 (1), 7-14.

de Guzman, R.C., Tsuda, S.M., Ton, M.-T.N., Zhang, X., Esker, A.R., Van Dyke, M.E. 2015. Binding interactions of keratin-based hair fiber extract to gold, keratin, and BMP-2. PLoS One 10 (8) e0137233-e0137233.

Dyer, J.M., Bell, F., Koehn, H., Vernon, J.A., Cornellison, C.D., Clerens, S., Harland, D.P., 2013. Redox proteomic evaluation of bleaching and alkali damage in human hair. Int. J. Cosmet. Sci. 35 (6), 555-561.

Elias, H.G., 2013. Macromolecules: Volume 2: Synthesis, Materials, and Technology. Springer US.

Fernandes, M., Cavaco-Paulo, A., 2012. Protein disulphide isomerase-mediated grafting of cysteine-containing peptides onto over-bleached hair. Biocatal. Biotransform. 30 (1), 10-19.

Fernandes, M.M., Lima, C.F., Loureiro, A., Gomes, A.C., Cavaco-Paulo, A., 2012. Keratin-based peptide: biological evaluation and strengthening properties on relaxed hair. Int. J. Cosmet. Sci. 34 (4), 338-346.

Galli, C.L., Bettin, F., Metra, P., Fidente, P., De Dominicis, E., Marinovich, M., 2015 Novel analytical method to measure formaldehyde release from heated hair straightening cosmetic products: impact on risk assessment. Regul. Toxicol. Pharmacol. 72 (3), 562-568.

Gavazzoni Dias, M.F.R., 2015. Hair cosmetics: an overview. Int. J. Trichol. 7 (1), 2-15.

Gill, I., López-Fandiño, R., Jorba, X., Vulfson, E.N., 1996. Biologically active peptides and enzymatic approaches to their production. Enzym. Microb. Technol. 18 (3), $162-183$.

Goddard, E., 1999. Principles of Polymer Science and Technology in Cosmetics and Personal Care. London_CRC Press.

Hans-Dieter, J., Peter, K., Andreas, K., 1985. Basic principles of protease-catalyzed peptide bond formation. Angew Chem. Int. Ed. Engl. 24 (2), 85-93.

Hansen, R.E., Østergaard, H., Nørgaard, P., Winther, J.R., 2007. Quantification of protein thiols and dithiols in the picomolar range using sodium borohydride and 4,4'-dithiodipyridine. Anal. Biochem. 363 (1), 77-82.

Harrison, S., Sinclair, R., 2003. Hair colouring, permanent styling and hair structure. J. Cosmet. Dermatol. 2 (3-4), 180-185. 
Illanes, A., Guzmán, F., Barberis, S., 2010. Proteases as powerful catalysts for organic synthesis, amino acids. Pept. Protein Org. Chem. 2, 339-377.

Kaur, B.J., Singh, H., Lin-Greenberg, A., 2002. Irritant contact dermatitis complicated by deep-seated staphylococcal infection caused by a hair relaxer. J. Natl. Med. Assoc. 94 (2), 121-123.

Kim, Y.-D., Jeon, S.-Y., Ji, J.H., Lee, W.-S., 2010. Development of a classification system for extrinsic hair damage: standard grading of electron microscopic findings of damaged hairs. Am. J. Dermatopathol. 32 (5), 432-438.

Kobayashi, S., Makino, A., 2009. Enzymatic polymer synthesis: an opportunity for green polymer chemistry. Chem. Rev. 109 (11), 5288-5353.

Lau, J.R.H., 1997. Hair Care Perming Agent Inc. (Wooster, OH) 5690956 United State.

Lee, Y., Kim, Y.-D., Pi, L.-q., Lee, S.Y., Hong, H., Lee, W.-S., 2014. Comparison of hair shaft damage after chemical treatment in Asian, White European, and African hair. Int. J. Dermatol. 53 (9), 1103-1110.

Li, G., Raman, V.K., Xie, W., Gross, R.A., 2008. Protease-catalyzed Cooligomerizations of l-leucine ethyl ester with l-glutamic acid diethyl ester: sequence and chain length distributions. Macromolecules 41 (19), 7003-7012.

Li, L., 2009. MALDI Mass Spectrometry for Synthetic Polymer Analysis. Wiley.

Ma, B., Qiao, X., Hou, X., Yang, Y., 2016. Pure keratin membrane and fibers from chicken feather. Int. J. Biol. Macromol. 89, 614-621.

Maneli, M.H., Smith, P., Khumalo, N.P., 2014a. Elevated formaldehyde concentration in "Brazilian keratin type" hair-straightening products: a cross-sectional study. J. Am. Acad. Dermatol. 70 (2), 276-280.

Maneli, M.H., Smith, P., Khumalo, N.P., 2014b. Elevated formaldehyde concentration in "Brazilian keratin type" hair-straightening products: a cross-sectional study. J. Am. Acad. Dermatol. 70 (2), 276-280.

McMichael, A.J., 2007. Hair breakage in normal and weathered hair: focus on the black patient. J. Investig. Dermatol. Symp. Proc. 12 (2), 6-9.

Meng, L.P., Joshi, R., Eckstein, H., 2007. Protease-catalyzed synthesis of the tripeptide CCK26-28, a fragment of CCK-8. Amino Acids 33 (1), 91-96.

Miranda-Vilela, A.L., Botelho, A.J., Muehlmann, L.A., 2014. An overview of chemica straightening of human hair: technical aspects, potential risks to hair fibre and health and legal issues. Int. J. Cosmet. Sci. 36 (1), 2-11.

Nogueira, F., Piskin, E., Teixeira, P., Gouveia, I., 2014. New Strategies for Surface Modification of Cotton and Silk Textiles with Antimicrobial Properties.

Nourbakhsh, S., Ashjaran, A., 2012. Laser treatment of cotton fabric for durable antibacterial properties of silver nanoparticles. Materials 5 (7), 1247-1257.

Olasode, O., 2009. Chemical hair relaxation and adverse outcomes among Negroid women in South West Nigeria. J. Pak. Assoc. Dermatol. 19, 203-207.
Polaina, J., MacCabe, A.P., 2007. Industrial Enzymes: Structure, Function and Applications. Springer, Dordrecht, The Netherlands.

Qi, H., Zhao, C., Qing, F.-l., Yan, K., Sun, G., 2016. Antiwrinkle finishing of cotton fabrics with 5-(carbonyloxy succinic)-benzene-1,2,4-tricarboxylic acid: comparison with other acids. Ind. Eng. Chem. Res. 55 (46), 11850-11856.

Qin, X., Khuong, A.C., Yu, Z., Du, W., Decatur, J., Gross, R.A., 2013a. Simplifying alternating peptide synthesis by protease-catalyzed dipeptide oligomerization. Chem. Commun. 49 (4), 385-387.

Qin, X., Xie, W., Su, Q., Du, W., Gross, R.A., 2011. Protease-catalyzed oligomerization of l-lysine ethyl ester in aqueous solution. ACS Catal. 1 (9), 1022-1034.

Qin, X., Xie, W., Tian, S., Cai, J., Yuan, H., Yu, Z., Butterfoss, G.L., Khuong, A.C. Gross, R.A., 2013b. Enzyme-triggered hydrogelation via self-assembly of alternating peptides. Chem. Commun. 49 (42), 4839-4841.

Ribeiro, A., Matamá, T., Cruz, C.F., Gomes, A.C., Cavaco-Paulo, A.M., 2013. Potential of human $\gamma \mathrm{D}$-crystallin for hair damage repair: insights into the mechanical properties and biocompatibility. Int. J. Cosmet. Sci. 35 (5), 458-466.

Robbins, C.R., 2002. Chemical and Physical Behavior of Human Hair, fourth ed. Springer, Berlin.

Secchi, G., 2008. Role of protein in cosmetics. Clin. Dermatol. 26 (4), 321-325.

Shirgholami, M.A., Karimi, L., Mirjalili, M., 2016. Multifunctional modification of wool fabric using graphene/TiO2 nanocomposite. Fibers Polym. 17 (2), $220-228$.

Sinclair, R.D., 2007. Healthy hair: what is it? J. Investig. Dermatol. Symp. Proc. 12 (2), $2-5$.

Uyama, H., Fukuoka, T., Komatsu, I., Watanabe, T., Kobayashi, S., 2002. Proteasecatalyzed regioselective polymerization and copolymerization of glutamic acid diethyl ester. Biomacromolecules 3 (2), 318-323.

Villa, A.L.V., Aragão, M.R.S., dos Santos, E.P., Mazotto, A.M., Zingali, R.B., de Souza, E.P., Vermelho, A.B., 2013. Feather keratin hydrolysates obtained from microbial keratinases: effect on hair fiber. BMC Biotechnol. 13 (1), 15.

Viswanathan, K. Omorebokhae, R., Li, G. Gross, R.A., 2010. Protease-catalyzed oligomerization of hydrophobic amino acid ethyl esters in homogeneous reaction media using l-phenylalanine as a model system. Biomacromolecules 11 (8), 2152-2160.

Wolfram, L.J., 2003. Human hair: a unique physicochemical composite. J. Am. Acad. Dermatol. 48 (6), S106-S114. Supplement.

Yu, J., Yu, D.-W., Checkla, D.M., Freedberg, I.M., Bertolino, A.P., 1993. Human hair keratins. J. Investig. Dermatol. 101 (1), S56-S59. Supplement. 